\title{
Una familia
}

criptojudía del interior

de Portugal ante una

visita inquisitorial.

São Vicente da Beira,

junio de 1579

A Crypto-Jewish Family from the Portuguese Countryside in front of an Inquisitorial Visit. São Vicente da Beira, June of 1579

DOI: https://doi.org/10.22380/20274688.946

Recibido: 26 de agosto del 2019

Aprobado: 12 de marzo del 2020
RICARDO ESCOBAR QUEVED0*

Collège de France, París

ricardo.escobar@college-de-france.fr

\section{R E S U M E N}

La relativa tranquilidad en la que habían vivido los judaizantes de la comarca de Castelo Branco durante más de ochenta años se acabó de tajo entrando el verano del año 1579, cuando el inquisidor Marcos Teixeira atravesó esas tierras fronterizas instando a la población a la denuncia. A partir de entonces, la represión inquisi- torial contra la herejía no dará respiro, los arrestados y los muertos se contarán por centenas, otros más partirán buscando refugio en Sevilla y el Nuevo Mundo. Nos proponemos observar aquí las prácticas judaizantes, según los testimonios recogidos por el inquisidor, así como las consecuencias judiciales de la visita.

* Doctor en Historia y Civilizaciones de l’École des Hautes Études en Sciences Sociales, París; investigador asociado al Institut des Civilisations du Collège de France. Fue Chargé de Conférences en l'EPHE, Section de Sciences religieuses, sobre la historia de la diáspora criptojudía. En el 2008 la Universidad del Rosario publicó su libro Inquisición y judaizantes en América española, siglos XVI-XVII. 
Palabras clave: cristianos nuevos, Inquisición, Castelo Branco, criptojudaísmo, judaizantes

\section{$\begin{array}{llllllll}\mathbf{A} & \mathbf{B} & \mathbf{S} & \mathbf{T} & \mathbf{R} & \mathbf{A} & \mathbf{C} & \mathbf{T}\end{array}$}

The relative tranquil life led by the $\mathrm{Ju}$ daizers of the District of Castelo Branco ended in the spring of 1579 with the arrival of the Inquisitor Marcos Teixeira, who urged the inhabitants to denounce heretics. Consequently, the inquisitorial repression of heretics was relentless and the prisoners and dead will number hundreds; many sought refuge in Seville and the New World. We will observe the Judaizer practices through testimonies collected by the Inquisitor and the judicial consequences of the Visit.

Keywords: new Christians, Inquisition, Castelo Branco, Crypto-Judaism, Judaizers

\section{Introducción}

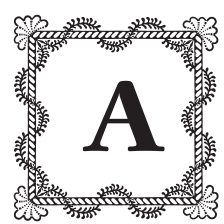

finales del siglo Xvi, cumpliendo casi una centuria de haber sido prohibido, el judaísmo ibérico sobrevivía, con diversa fortuna, confinado en una vida subterránea. Para entonces, ya hacía mucho tiempo que el capítulo español había sido cerrado por la represión inquisitorial, y lo que quedaba del judaísmo ibérico existía casi exclusivamente gracias al portugués, aun aquel que comenzaba a manifestarse de nuevo en suelo español o en sus dominios americanos.

El caso del Nuevo Mundo español es justamente una prueba flagrante de esa nueva preponderancia lusitana, pues la casi totalidad de las personas juzgadas allí en el curso del primer siglo de funcionamiento del Santo Oficio (I569-I669) fueron portugueses, ya fuera de nacimiento o de ascendencia directa. Uno de los aspectos más sugestivos, en lo que hace a esos procesados americanos, es el importante número de los que declararon ser oriundos de la modesta comarca de Castelo Branco (hoy en día distrito), en Portugal, así como la proliferación de lazos familiares entre ellos. Remontando en el pasado de esas familias, a través de los procesos incoados por el Santo Oficio portugués, llegamos a lo que fue un momento determinante para su historia, un punto de quiebre: la visita inquisitorial efectuada en 1579 .

I Sumaron 6I7 individuos, según las cifras que avancé en los apéndices de Inquisición y judaizantes en América española, siglos XVI-XVII. 
Al tiempo que seguimos la visita, el primer objetivo de este artículo es el de observar las prácticas judaizantes, tal y como aparecían a los ojos de los católicos que denunciaron; veremos, en segunda instancia, cuáles fueron las consecuencias judiciales, a través de los procesos que el Santo Oficio inició contra los denunciados en los años que siguieron. Los pormenores de la visita, que será el prólogo de una represión masiva y prolongada, y de su corolario, la emigración forzada, están consignados en un documento que, a través de cientos de testimonios, nos bosqueja además una especie de "retrato hablado" de aquellos pueblos de la provincia portuguesa profunda, donde la población católica de cepa cohabitaba con una importante minoría de cristianos nuevos ${ }^{2}$ de origen judío. Para ganar en nitidez decidimos concentrarnos en un pueblo, Sáo Vicente da Beira, y en una familia cristiana nueva, a la que identificaremos como Lucena ${ }^{3}$.

São Vicente era en la época un pueblo de mediana envergadura, comparable a otros de la región, como Penamacor o Monsanto. Parte de su población se concentraba en el casco urbano, la otra estaba dispersa en las faldas de la sierra de la Gardunha. Era un hábitat tosco, de clima húmedo, y el suelo granítico estaba principalmente cubierto de castaños. Pensamos que podría contar entonces con una población cercana a las 2.000 personas, partiendo del censo fiscal de I496, que contaba 35I "fuegos", y que proyectamos al alza, tal como sucedió en otras poblaciones de la región que sí fueron censadas en 1527 (Alves I42).

No tenemos mayor certeza acerca del origen de la familia Lucena, pero nos inclinamos por uno español ${ }^{4}$. Podemos imaginar que venían de la ciudad

2 Se denominaba así a los convertidos recientemente al catolicismo o a sus descendientes. A pesar de la prohibición del judaísmo a finales del siglo xv, algunos de esos cristianos nuevos continuaron practicándolo secretamente (criptojudíos), designados por el Santo Oficio como judaizantes, término a la vez teológico y jurídico.

3 En realidad, se trata de múltiples enlaces entre los Lucena y los Lopes (siempre conservaremos la ortografía original), pero el apellido Lucena será preponderante. No había en ese entonces una regla en cuanto hace a la transmisión de los apellidos, de tal manera que podemos encontrar en una misma hermandad tantos apellidos como hijos: unos guardando el paterno, otros el materno, otros más recuperando el de una abuela, o aún más allá, sin olvidar aquellos que agregaron el nombre de una ciudad. En el siglo XVIII aparece de nuevo el Lucena en este linaje, aunque con menos regularidad.

$4 \quad$ No encontramos traza del apellido Lucena en los archivos de la Inquisición portuguesa anteriores a 1579; tampoco en los múltiples estudios sobre los judíos portugueses en la Edad Media. En la España de finales del siglo XV sí, según consta en un proceso adelantado en I 49I contra Juan Ramírez Lucena (Cantera II3). También en un asunto de "alumbradismo", del que acusaban a Petronila Lucena y sus hermanos, señalados como "conversos de origen judío" por el tribunal de Toledo en I534 (Pastore 5I-73). 
andaluza del mismo nombre, aquella donde brilló el judaísmo en la Edad Media, y que fueron empujados al exilio a causa de los pogromos y las conversiones forzadas que asolaron a España desde finales del siglo xiv. El nuevo hogar de los Lucena que emigraron hacia Portugal parece estar repartido entre la ciudad de Castelo Branco y el pueblo de São Vicente da Beira, que es como su apéndice, distantes el uno del otro apenas unas seis leguas'. Allí, sumidos ya en una vida espiritual encubierta luego de la prohibición del judaísmo en I497, construyeron una nueva memoria.

Sobre el plan geopolítico, recordemos que en la época de la visita se abría una coyuntura de cambios importantes y en ocasiones paradójicos, ya que la intensa fase represiva desarrollada por la Inquisición portuguesa en los años siguientes, será mitigada por una serie de medidas que favorecerán a los cristianos nuevos. En primera instancia, la unificación de los reinos ibéricos bajo la corona de Felipe II en I580, les va a entreabrir las puertas de España; el déficit estructural del Estado, necesitado de líquido, abrió más la brecha en los años que siguieron. En I60I, los cristianos nuevos portugueses pagaron para que se abolieran los obstáculos a su emigración, y en 1605 obtuvieron un indulto papal para los acusados de judaizar, a cambio de dos millones de cruzados que, casi en su totalidad, fueron a parar a las arcas de Felipe III. También les favoreció la reorganización del comercio de esclavos, a partir de 1595, bajo el régimen de asientos, en el cual los cristianos nuevos tuvieron un papel preponderante. Las puertas del Nuevo Mundo español, que les había estado vedado, al menos oficialmente, se abrían así para estos portugueses cristianos nuevos que, al tiempo que sufrían la persecución del Santo Oficio, lograban un ascenso social sin precedentes en el primer tercio del siglo XVII. La caída en desgracia del conde-duque, quien se había apoyado en los financistas cristianos nuevos, y la secesión portuguesa de 1640 marcarán el fin de esta coyuntura.

5 Esta interdependencia venía desde la Edad Media, ya que, como se puede observar en los censos de la época, las dos juderías cotizaban unidas al Fisco Real. Los 23.000 reales que pagaron muestran su importancia, en comparación con Monsanto, que pagaba 4.000 , o Belmonte con apenas 400 (Castelo 17; Ferro 381). 


\section{Las visitas inquisitoriales}

Fundado en 1536, el Santo Oficio portugués tuvo una actividad relativamente reducida durante las primeras décadas de su existencia, como lo prueba el hecho de que hasta 1560 únicamente cuatro autos de fe se habían celebrado en Évora y apenas uno en Lisboa. Desde Roma el pontificado vigilaba la evolución del proyecto portugués y, cuando lo consideró conveniente, intervino para moderar su actividad. Para la prueba están los cuatro perdones generales que promulgó en menos de tres lustros.

Las diferencias entre las dos inquisiciones ibéricas son notorias en cuanto hace a la política de ocupación del espacio. Si en España más de una veintena de tribunales diseminados a través del reino garantizaban un cubrimiento equilibrado, en Portugal solo tres se encargaban de la vigilancia del conjunto del territorio. Esquemáticamente, el tribunal de Coímbra se encargaba de la zona norte, el de Lisboa, de la del centro (además de Brasil), mientras que el de Évora miraba hacia el sur. Por su situación descentrada, algunas regiones próximas de la frontera con España, reconocidas por la fuerte densidad de población cristiana nueva y, en consecuencia, de la herejía que siempre estuvo tácita en ella, la judaizante, se encontraron relativamente al abrigo de la represión inquisitorial.

Para paliar esta ausencia en la periferia de los tribunales, el Consejo General de la Inquisición portuguesa promovió lo que se llamó las visitas de distrito, encargadas, antes que de cualquier actividad represiva directa, de expandir la acción de la institución, recolectando denuncias que serían explotadas posteriormente por el tribunal concernido. Una fórmula que por su austeridad y su movilidad podría rememorar más bien a la Inquisición medieval, pero que gracias al contacto directo con la población y a la sistematización de la información resultó de una gran eficacia. Según estaba estipulado en los regimentos, una visita se componía de uno o dos inquisidores "de conocidas letras y autoridad", un notario, un oficial de justicia con dos hombres y un solicitador (Oltean 34).

La más impresionante y eficaz de esas visitas fue aquella que, bajo la dirección del inquisidor Marcos Teixeira, comenzó el 26 de diciembre de 1578 en la ciudad de Portalegre. Catorce meses duró la épica travesía del inquisidor, a lo largo de veintiocho municipios, pertenecientes a tres obispados y dependientes de tres tribunales diferentes. Pocos inquisidores mostraron tal tesón en la defensa del catolicismo; pocos los que fueron a escuchar las quejas de ese campesino católico olvidado en la provincia portuguesa. 
En pocas palabras, ¿cómo funcionaba esa visita? Guiados por el intercambio previo con diversas autoridades eclesiásticas de la región, Marcos Teixeira y su comitiva se desplazaban de pueblo en pueblo y pasaban en cada uno de ellos estadías relativamente cortas, durante las cuales escuchaban, en audiencias privadas, las denuncias de los habitantes que se presentaban a hacerlo más o menos voluntariamente. En realidad, el libre arbitrio de los moradores había sido trabajado con anterioridad para encaminarlo hacia la colaboración con el Santo Oficio: el edicto de fe, publicado antes de cada visita, obligaba a todo católico, bajo la amenaza de prisión y excomunión, a denunciar cualquier acto contrario a la religión que hubiera presenciado o del que tuviera noticia.

\section{Las fuentes documentales}

La visita del inquisidor Marcos Teixeira quedará consignada en un documento conservado en los Archivos Nacionales de Torre do Tombo en Lisboa, que será la fuente principal de este artículo: el Livro $I^{\circ}$ das denúncias da visitação do Santo Oficio nas ilhas dos Açores, Alentejo e Beira (ANTt, TSO-IL/038/0794, en adelante Visitação), en el cual se recogen, de manera sucinta y metódica, las acusaciones de los habitantes que se presentaron ante el tribunal itinerante. A pesar de la precariedad material, las audiencias se tenían con el rigor que caracterizaba a todo procedimiento inquisitorial, de lo que resulta un documento estereotipado sobre la forma, pero extremadamente concreto, que rara vez pasa de dos folios por denunciante. En las primeras líneas este comenzaba por identificarse con precisión, declarando el nombre y el apellido, la profesión (si era mujer, la del esposo), el "origen" (es decir, si era cristiano viejo o nuevo), la edad, y, finalmente, el lugar donde residía. Procedía enseguida a describir de manera sumaria los hechos que denunciaba, el lugar donde ellos habían tenido lugar y su duración. Identificaba por último a los acusados, con nombre, lugar de residencia y profesión, o, en su defecto, por su descripción física. En esta memoria lo que oímos es la voz del pueblo católico de la provincia, antes de que fuera pasada por el cedazo de la jurisprudencia inquisitorial, que apartará los testimonios singulares, aquellos no probados o los que parecían ser producto de enemistades. Es una palabra en bruto, ese es su defecto y su gran cualidad.

Los procesos inquisitoriales, que utilizamos para apreciar los resultados judiciales de la visita, son considerados, por su volumen, en general de varios cientos de folios, y los detalles que recogen, los documentos más importantes 
para el estudio de las causas de fe. En estos se hayan registrados todos los pormenores de la causa, que en general duraba años, desde la captura hasta el acto de abjuración, pasando por las audiencias, la publicación de testigos y las sesiones de tortura. Los procesos también son imprescindibles para reconstruir las genealogías de los acusados y establecer los lazos de parentesco entre unos y otros. Los procesos portugueses guardan prácticamente el mismo esquema que el usado en los tribunales hispanoamericanos, aunque son más sintéticos. Ello es particularmente notorio en el capítulo consagrado a la sentencia, muy sumario en el caso portugués, en el que rara vez pasa de dos páginas, aun en los casos de condenas a muerte.

\section{La visita atraviesa la región de la Beira}

A inicios de la primavera de 1579, Teixeira y su comitiva atravesaron el río Tajo y se adentraron en la Beira, esos territorios ondulados que se prolongan hasta el Duero por el norte y la sierra de la Estrella al oeste, bordeando la frontera española. Covilhã y Castelo Branco eran dos ciudades que se destacaban desde la Edad Media por la importancia de sus comunidades judías. La primera, al norte, era la más dinámica sobre el plano económico, gracias a su industria lanífera ${ }^{6}$, y en aquella época, cuando el judaísmo era todavía permitido, contaba con la presencia de un delegado (ouvidor) del Rabinado Mayor de Lisboa, encargado de juzgar, según la ley mosaica, las causas civiles y criminales entre judíos. En sus alrededores, hacia el sur, se halla Fundão, seguida de São Vicente, que de estas cuatro es la población más modesta, tradicionalmente dependiente de Castelo Branco. Una miríada de veredas y pequeños pueblos, donde residían importantes minorías cristianas nuevas, giraban en torno a esos dos centros de gravedad.

Luego de haber visitado el poblado de Nisa, entre el 4 y el i2 de marzo de 1579, Marcos Teixeira y su séquito pasaron a Abrantes y entraron de esta manera en el obispado de La Guarda. Después, pasaron tres días en Sarzedas, donde hubo veintiocho denunciados, y llegaron el i3 de abril a la ciudad de Castelo Branco. Después de cuatro penosos meses de viaje en pleno invierno,

6 Covilhã era la más poblada, según consta en la memoria de los impuestos de almojarifazgo cobrados en el año I 496: tenía 2.234 moradores (o fogos, término que designa a una persona de sexo masculino, cabeza de familia), de los cuales ro 8 pagaban impuesto en su calidad de judíos. Castelo Branco contaba con 820 moradores (Carvalho I). 
hospedada en modestas casas parroquiales, la comitiva inquisitorial pudo al fin disfrutar de una cierta comodidad en el monasterio de São António. Castelo Branco, con más de I.20o fuegos, era una población que por su vitalidad demográfica ya había desbordado el viejo casco urbano amurallado por la orden de los templarios en épocas de la reconquista.

Si los pueblos que le precedieron dejaron entrever la existencia de prácticas heréticas, en Castelo Branco el problema era de otra dimensión, y allí los inquisidores encontraron a los buenos cristianos que permitieron activar la máquina inquisitorial. Sin los ojos de la población, el Santo Oficio estaba como ciego. La primera denunciante que se presentó ante el inquisidor Teixeira en Castelo Branco fue Maria de Oliveira, mitad cristiana nueva, quien denunció a treinta personas, la mayoría parientes suyos, de entregarse a prácticas judaizantes ${ }^{7}$. Al término de la visita, IO3 vecinos de Castelo Branco se habían presentado ante la mesa inquisitorial: algo más de 200 testimonios concernían a actos ligados al criptojudaísmo, en tanto que otros i8 lo eran por delitos menores propios de cristianos viejos. El número era elevado, teniendo además en cuenta la migración constante hacia reinos donde podían practicar libremente el judaísmo ${ }^{8}$.

El 28 de abril, Teixeira dio por terminado su trabajo en Castelo Branco y al día siguiente retomó la ruta hacia el oriente, hasta Idanha-a-Nova, a donde llegó el r. ${ }^{\circ}$ de mayo. En diez días, apenas un puñado de denuncias concernían a judaizantes, entre ellas una contra Marta de Lucena, una viuda proveniente de São Vicente. El in de mayo la visita llegó a Rosmaninhal, bordeando la frontera española, y el i8 tomó de nuevo la ruta del norte hasta Monsanto, a donde únicamente fueron llevadas ante el tribunal ciertas querellas entre cristianos viejos. Es sorprendente que no hubiese allí denuncias contra cristianos nuevos, siendo otrora Monsanto la sede de una floreciente comunidad judía, autorizada $\mathrm{y}$ a ese título gravada fiscalmente hasta fines del siglo $\mathrm{Xv}^{9}$.

7 A diversos grados, estos cristianos nuevos colaboradores del Santo Oficio (llamados comúnmente malsines), estarán detrás de los golpes más contundentes asestados a los grupos criptojudíos.

8 El inquisidor general Jorge de Almeida hablaba de más de 3.000 cristianos nuevos que se habían “ausentado" del reino (Marcocci y Paiva 69). Entre los que dejaron Castelo Branco en la primera mitad del siglo Xvi recordemos a dos médicos notables: Amatus Lusitanus y Elie Montalto. Dos portugueses “de Castiblanco" fueron señalados en el Nuevo Reino de Granada hacia 1560, en la fundación de la villa de Remedios, Antioquia: eran Andrés Vaz, "feroz combatiente contra los indios", y Diego Pinto. Aunque no hay certeza, son dos apellidos muy comunes entre cristianos nuevos (Aguado 372, 375).

9 Pagaron 4.000 reales en 1496 (Carvalho 5). En realidad, todo parece indicar que aquí los judaizantes sí protegieron el secreto, al menos durante un tiempo; luego, ya en el siglo xviri, el criptojudaísmo 
Cuatro días más tarde, Marcos Teixeira y su comitiva llegaban a Penamacor. Aquí solo hubo un par de denuncias, contra una familia que vivía en el vecino pueblo de São Vicente, la de la viuda Beatriz Fernandes y las cuatro hijas que había tenido con Diego de Lucena.

\section{La visita en São Vicente}

Tres días más tarde, el inquisidor y su comitiva llegaban a São Vicente, donde el 7 de junio de 1579 recibían las primeras denuncias. Previamente, como lo establecían los regimentos, se había publicado el edicto de fe, ese minucioso catálogo donde se describían las herejías y la forma de identificarlas. Regularmente, Teixeira citaba este documento con cierta solemnidad para inducir al testigo a la denuncia, preguntándole: "Si sabía de alguna persona o personas que dijesen o hiciesen alguno de los errores y crímenes contenidos en el Edicto general de la fe que se publicó" (Visitação, ff. 603 y 606, por ejemplo).

En Sáo Vicente 78 habitantes se presentaron para denunciar a aquellos que durante años habían sido sus vecinos, socios o patrones; a veces sus amigos. Es una cifra importante para un pueblo modesto, el signo de una fractura. A título de comparación, en Covilhâ, con una población cinco a seis veces superior y una proporción similar de cristianos nuevos, hubo 8I denunciantes (Mea 237).

El ritmo de las denuncias fue in crescendo: tres testigos se presentaron el primer día. Luego la afluencia fue aumentando diariamente: siete testigos el segundo, diez el tercero, once el siguiente. La jornada del i2 de junio, Teixeira no daba abasto: veintisiete denunciantes fueron recibidos y jurados.

Para resumir nuestras estadísticas sobre ese grupo de 78 denunciantes, debemos señalar que el $5 \mathrm{I} \%$ eran hombres, la mayoría personas casadas o viudas.

Una estadística importante es la del "origen" del denunciante: 6r \% de ellos declararon ser cristianos viejos, uno solo reconoció ser cristiano nuevo, Gil Antunez, católico ferviente, y quien denunciará abundantemente. En quince de los denunciantes no está especificado, pero pensamos que sería imposible que fueran cristianos nuevos y ello no se señalara. La edad promedio era de 32 ańos.

La mayoría de los denunciantes era de estrato humilde: casi la mitad declararon ser labradores $(22 \%)$ y artesanos (23\%); hubo dos mercaderes y seis

parece renacer de sus cenizas y con él la represión inquisitorial. 
rentistas. Unos cuantos pertenecían a lo que podríamos catalogar de élite provinciana: tres eran escribanos, dos eclesiásticos y uno era juez. Hay finalmente un testigo poco ordinario en estos territorios del interior que vale la pena resaltar: se trata de un esclavo africano, Bastiáo Preto de Manicongo, quien servía en casa de la familia Lucena-Lopes. Su presencia recuerda la fuerte implicación portuguesa en el comercio de esclavos y el desempeño de africanos en labores domésticas, aun en regiones alejadas de la costa como esta.

Aunque el oficio de las mujeres denunciantes no está nunca especificado (sí el del marido), de diferentes testimonios se deduce que varias de ellas habían trabajado como empleadas en casa de los acusados. Había sido ese contacto cotidiano el que les había permitido observar los gestos y las palabras sospechosas, el que había creado una cierta familiaridad y un relajamiento de los judaizantes.

\section{La vida criptojudía a los ojos de los católicos}

La primera constatación sobre los resultados de la visita en São Vicente, asombrosa para cualquier estudioso del criptojudaísmo, es el volumen de hechos denunciados, que llegó a I45 (hay hechos que pueden ser denunciados en varias ocasiones).

Tres rituales destacados de la tradición criptojudía peninsular han sido identificados por los cristianos viejos, aunque no siempre puedan ponerle un nombre: la guarda del sábado (shabat) (34\% de hechos denunciados); el día grande (kipur) (I4\%); y un tercer conjunto, más difuso, pero importante, concierne a las prácticas funerarias (3I \%). En cuanto hace a las prohibiciones alimenticias, seis personas fueron denunciadas por ayunar, dos por evitar comer cerdo y una decena por comer carne en cuaresma. Curiosamente, no hay denuncias sobre la confección del pan ácimo para la fiesta de Pésaj, que fue muy común en estos grupos judaizantes y que aparece en varias sentencias. Esta ausencia les da más veracidad a las denuncias; confirma que no están utilizando el edicto de fe (donde está detallado el ritual de la preparación del pan) para darle credibilidad a su testimonio. 


\section{El shabat y el kipur}

Por su frecuencia y modalidades, la guarda del sábado fue la práctica más visible a los ojos de los cristianos viejos. Denunciaban a los cristianos nuevos por llevar camisas lavadas los sábados y pasearse todo el día por las calles del pueblo sin trabajar. La víspera también cambiaban las sábanas y barrían la casa, además de encender candelabros que preparaban cuidadosamente con mechas y aceite limpios. Las argucias de ciertas mujeres parecen haber sido claramente identificadas por los denunciantes, como la de acudir los sábados por la mañana a la misa de la Concepción muy engalanadas, evitando de esta manera el trabajar (denuncia de Manuel Rodrigues, Visitação, f. 587).

El ritual correspondiente al kipur fue muy popular entre los judaizantes, tal como se desprende de las sentencias condenatorias que se dictaron luego de esta visita. En la boca de los denunciantes se habla del "Día de los judíos", o simplemente de reuniones que se celebraban "un día por septiembre"; también se habla del "Día de las perdonanzas", y encontramos un notable que avanzó la noción de "Dia Judeorum" (denuncia de Pero Vaz, Visitação, f. 592). Algunas de esas celebraciones que seguían al ayuno de kipur fueron memorables, como la que se realizó tres años atrás en casa de Beatriz Fernandes, viuda de Diego de Lucena, reconocida por sus conocimientos de la ley de Moisés, quien, decía la testigo, era "como la reina de todas las cristianas nuevas de esta tierra" (denuncia de Violante Rodrigues, Visitação, f. 569). Agregaba otra vecina que ese día de septiembre, un martes, recordaba, pocos días después del día de san Miguel, los cristianos nuevos se habían reunido en casa de la viuda, y para todos era "como día de fiesta", y hasta habían venido parientes de otros pueblos cercanos (denuncia de Leonor Lopes, Visitação, f. 569).

\section{Los ritos funerarios}

Este es sin duda el capítulo más original y merece en consecuencia que lo detallemos. Su visibilidad obedece en primera instancia a que la muerte de un practicante implicaba una serie de rituales colectivos, seguidos de una ceremonia de inhumación que era forzosamente pública. Apenas un testimonio habla del momento que precedía la muerte: fue el de Gracia Rodrigues (Visitação, ff. 593-594), quien presenció la agonía de Duarte Rodrigues, durante la cual su hermana Beatriz, muy doliente, permanecía sentada en su cama "sin nombrar 
nunca Jesús ni nuestra Señora, moviendo los labios, abriendo y cerrando los ojos y las manos, y haciendo movimientos con el cuerpo y la cabeza, levantándola y bajándola por espacio de media hora”.

Los rituales que seguían a la muerte de un cristiano nuevo eran muy visibles, lo que aparte del fondo de herejía que ello conllevaba, parecía exacerbar la indignación de la población católica, como lo expresaba un testigo ante los inquisidores: "que todo esto es notorio en esta villa, que no se habla de otra cosa y hay escándalo de ello" (denuncia de Ruy Brito, Visitação, f. 576). Así, las denuncias con mayor número de acusados corresponden a rituales funerarios, como los diecisiete que se encontraban reunidos después de la muerte de la viuda Beatriz Fernandes, personaje central de la comunidad criptojudía. Según la denunciante, vecina de la muerta, estas reuniones se habían prolongado durante los ocho días de duelo que siguieron al deceso, en los cuales algunos de ellos no salieron de la casa y los llevaban de afuera grandes ollas de comida, en tanto que Isabel de Lucena, hija de la difunta, hacía las veces de portera (denuncia de Branca Vaz, Visitação, ff. 588-589).

Otra denunciante relataba que tres años atrás había muerto Margarida Rodrigues, y que las cristianas nuevas andaban muy tristes y mal vestidas (se refiere únicamente a las mujeres), y que el martes siguiente se vistieron de fiesta y se reunieron en la tienda de Beatriz Fernandes, y estuvieron allí todo el día, a puerta cerrada, y no le abrieron a nadie, aunque era la tienda en la cual todo el pueblo se abastecía, y no cocinaron ni llevaron comida, y se escuchaba un rumor como de personas que rezaban (denuncia de Joana Rodrigues, Visitação, ff. 607-608).

Tres testigos que entraron en casa del difunto Simáo Fernandes, panadero, para dar el pésame a su viuda, Clara Rodrigues, antes de que esta se mudara a Fundão, remarcaron que los deudos comían en una mesa baja, "como de un palmo de alto", sobre la que habían servido peces, huevos y garbanzos, y las mozas se ponían detrás de la puerta. Decía Inés Rodrigues, una de las denunciantes, que era la costumbre "luego de la muerte de uno de ellos, como lo hacen en esta tierra los cristianos nuevos" (denuncias de Rufina, Maria e Inés Rodrigues, Visitação, ff. 560, 568-569) ${ }^{\mathrm{I}}$.

Io Corresponde aquí a lo descrito en el edicto de fe español, pero que está ausente en el monitorio, su equivalente portugués. 
Luego de un deceso, los cristianos nuevos botaban el agua almacenada en la casa, y si era posible, la de todo el vecindario ${ }^{\text {II }}$ (denuncias de Isabel Jurdoa y Maria Migens, Visitação, ff. 580-595). Otra costumbre, que aparece también en el edicto de fe, fue revelada por una empleada de Lionel Rodrigues y Beatriz Anriques, una pareja de hosteleros, quien denunciaba que cuando murió la hija de sus patrones la enviaron a buscar un grano de aljófar que metieron en la boca de la muerta, antes de amortajarla (denuncia de Maria Felipe, Visitação, ff. 586).

\section{La inhumación}

Hablaremos ahora de uno de los rituales funerarios más insólitos de los denunciados en São Vicente. Se trata de una costumbre que ya había desaparecido en cualquier otra de las comunidades criptojudías implantadas a lo largo y ancho de los imperios ibéricos: la inhumación en tierra virgen. De acuerdo con varias denuncias recibidas en Sáo Vicente, los cristianos nuevos enterraban a sus muertos únicamente en tierra virgen, en el atrio o detrás de la capilla ${ }^{12}$. Jorge Machado, por ejemplo, clérigo de misa en São Vicente, denunciaba haber visto enterrar a Pero Vaz en la parte del atrio "donde no se acostumbra enterrar a ninguna persona si no es de su nación” (Visitaçâa, f. 590). Una práctica que rompía con la usanza de la época, que establecía que los muertos se enterraban en el interior de los edificios religiosos (Mas 53).

La tumba destinada para el judaizante fallecido era pues excavada únicamente en tierra virgen, buscándola muy profundamente, según enfatizan los testigos. Parece ser una costumbre limitada a Portugal, en aquel tramo del siglo XVI, ya que jamás ha sido citada, hasta donde tenemos conocimiento, en la historiografía concerniente al criptojudaísmo español. Otro de los requisitos de este ritual era que los trabajos de excavación fueran ejecutados tan solo por cristianos nuevos: "y no consienten que un cristiano viejo las haga" (denuncia de Violante Nunes, Visitação, f. 583). Se conservaría así la prohibición de contacto

II Una costumbre muy común también entre las comunidades judías askenazis de la época. Se decía que el ángel de la muerte limpiaba su espada en el agua y en consecuencia todo aquel que la tomaba moría (Amiel 269-272; Goldberg 266).

I2 Un testigo precisa que se trataba de la capilla de São Pedro, que correspondería a una que existió hasta el siglo XIX en la zona rural del pueblo. Allí enterraron a la madre de Simõa de Lucena (denuncia de Violante Nunes, Visitação, f. 583). 
con un no judío que "mancharía" el ritual. También se refiere que esta tarea de excavación se reservaba para los más pobres, de tal manera que cumplía también una función social, ayudando a los más necesitados de la comunidad. Era el caso de Gonzalo Vaz, hijo de Beatriz Fernandes, muy solicitado para estas tareas, quien se ganaba la vida como carretero (denuncia de Antonio Rodrigues, Visitação, f. 577).

\section{Cada uno en su ley}

Para finalizar este capítulo trataremos de una denuncia difícil de clasificar (y de ahí su interés), porque rebasa el ámbito exclusivamente religioso y sienta más bien una posición filosófica. El testimonio vino de la boca del esclavo Preto de Manicongo, quien relatara que durante una boda que se celebró en el pueblo de Alcains, dependiente de Castelo Branco, estando todos los Lucena presentes, había oído decir:

que en el mundo había judíos, cristianos, moros y gentiles, y todos afirmaban y asentían en que ninguna persona iba al infierno, mas que se salvaría cada uno en su ley. (Visitação, f. 564)

Una denuncia al parecer banal, pero que marcó el espíritu de los inquisidores, hasta el punto de que la consignaron en la sentencia contra Manuel de Lucena, acusado de ser el autor (ANTT, TSO-IL/O7I73, f. IO9). Como avanza Stuart Schwartz (34-36), esta expresión, corriente en la España del siglo XVI, da cuenta de la existencia de un relativismo religioso que perseveraba, aun en medios populares, más allá de fronteras religiosas. Si en este caso está en la boca de un cristiano nuevo de origen judío, también salió de la de cristianos viejos, y aun de musulmanes, quienes tal vez tenían que ver con el origen de la fórmula, porque una similar les era atribuida en el edicto de fe a los seguidores de "la secta de Mahoma", donde reza: "o que el moro se salva en su secta y el judío en su ley” (Medina 28).

El espíritu de tolerancia inherente a la afirmación de Manuel de Lucena parece bastante singular en aquella época, en la que cada religión quería garantizar la exclusividad del más allá. No solamente la religión católica, que, mayoritaria y sostenida por el poder, optó por la fuerza para extirpar cualquier disidencia, tanto en lo que hace a la vida como a lo que sigue: para ella, no hay salvación fuera de la Iglesia. También es un principio de exclusividad que 
se repite en la boca de miles de acusados de judaizar, quienes construyeron su edificio doctrinal sobre la base de que la ley de Moisés era la única buena para salvar el alma.

\section{Los acusados}

El número de personas denunciadas nominalmente en São Vicente ascendió a 95 (dejamos de lado tres acusaciones contra personas no identificadas formalmente); 52 eran mujeres, 43 hombres.

De ellos, 88, todos cristianos nuevos, eran señalados por prácticas criptojudías; los siete restantes eran cristianos viejos, acusados de otros delitos menores (ninguno fue encausado).

La gran mayoría vivía en São Vicente (6I), quince en Castelo Branco, cinco en Covilhã, tres en Alpedrinha, dos en Fundão, dos en Lisboa; algunos entre dos localidades.

No podemos sacar conclusiones sobre el oficio de los acusados, porque esta información no aparece en más de la mitad de las denuncias. Había mercaderes (16), artesanos (22) y otros (9); es de destacar que no hay ningún labrador, uno de los oficios más comunes entre los cristianos viejos denunciantes. Hay artesanos que parecen iniciarse en las artes del comercio, como Luis Dias, quien fue panadero y zapatero antes de lanzarse a la venta de mercancías que llevaba ocasionalmente a Lisboa. João Fernandes era sastre, panadero y comerciante. Hay dos hosteleros y dos tenderos. La única mujer acusada que aparece con un oficio específico es Joana Rodrigues, quien figura como botonera, lo que, como es el caso también de las cristianas viejas denunciantes, no quiere decir que las mujeres no trabajen, simplemente es una información que parece carecer de interés para los inquisidores.

La influencia que ganaban los cristianos nuevos en el mundo del comercio pudo haber creado una animosidad suplementaria entre los mercaderes cristianos viejos, que veían con malos ojos esa competencia. Es un hecho probado que, en otras latitudes, los celos comerciales sirvieron de aliciente para alimentar la máquina inquisitorial. No parece fortuito en todo caso que el primer denunciante que se presentó ante el inquisidor Teixeira en São Vicente fuera un comerciante, quien acusaba a los hermanos Gonzalo y Fernáo Vaz de haber avanzado ciertas proposiciones heréticas típicas de judaizantes en una posada 
donde hacían un alto, en viaje hacia Lisboa, donde llevaban un cargamento de castañas (denuncia de Silvestre Rodrigues, Visitação, f. 583).

\section{La hora de la represión}

A la visita de Teixeira le siguió un periodo de falsa calma, durante el cual la vida en São Vicente parece haber seguido su curso habitual. En ese lapso de tiempo, solo tres de los denunciados se habían ido del poblado. La gran mayoría, los que no quisieron o no pudieron ponerse a salvo, esperaron.

Del lado inquisitorial, el procedimiento siguió su curso, los testimonios recogidos durante la visita llegaron a los tribunales correspondientes. La zona de la Beira que nos interesa estaba en el límite de dos jurisdicciones inquisitoriales, la del Tribunal de Coímbra y la del de Lisboa, lo que hace que, por ejemplo, en la ciudad de Covilhã, durante el siglo xvi, hubiera procesados en los dos tribunales. Esta confusión jurisdiccional conlleva que la cronología de la represión aparezca desfasada en cuanto se refiere a los denunciados en São Vicente. El Tribunal de Coímbra, particularmente eficaz en aquel último cuarto del siglo XVI (Pereira 269-275) ${ }^{13}$, tardaría apenas unos meses en pasar a la acción, arrestando a dos mujeres, quienes habían sido denunciadas también en otro pueblo visitado: a Antónia Brandóa (en Penamacor), el is de enero de I580, quien fue reconciliada ${ }^{14}$ luego de pasar tres años en prisión (ANTT, TSO-IC/ 025/01745); después a Beatriz Henriques (en Monsanto), condenada también y enviada ańos más tarde de vuelta a Sáo Vicente, donde pasó tres años llevando el sambenito, el hábito de la infamia (ANTT, TSO-IC/O25/O4O35).

Las declaraciones de estas dos procesadas en Coímbra, "buenas confitentes", como se decía en el lenguaje inquisitorial, revelaron a los inquisidores los nombres y los pormenores del grupo judaizante de São Vicente. Con estas informaciones, el Tribunal de Lisboa pasaba a su vez a la ofensiva al inicio de 1582. Una orden de arresto contra nueve mujeres de Sáo Vicente, fechada del 23 de febrero, era enviada al comisario de la localidad, quien comenzaría a

I3 En este periodo r.834 personas fueron penitenciadas en Coímbra, 646 en Lisboa y 106 en Évora.

I La sentencia de "reconciliación" implicaba que el inculpado había reconocido la acusación del Tribunal y que, una vez pagada su falta, era reintegrado en el seno de la Iglesia. 
ejecutarla apenas unos días más tarde, a comienzos del mes de marzo (Proceso contra Joana Rodrigues, ANTT, TSO-IL/O28/09907, f. 3$)^{\text {I5 }}$.

En esta primera redada caerían Simóa de Lucena y sus cuatro sobrinas; el mes siguiente comenzarían los arrestos contra los parientes instalados en Castelo Branco. En total, 73 personas vecinas de São Vicente y Castelo Branco fueron arrestadas y llevadas a juicio en los ańos que siguieron a la visita de Teixeira. La mayor parte de estos condenados saldría al cadalso en dos autos de fe celebrados en Lisboa, el primero el 6 de mayo de 1584 , el segundo el I. ${ }^{\circ}$ de junio de 1586. Tres mujeres fueron condenadas a perecer en la hoguera ${ }^{16}$. Es preciso resaltar que no había ningún caso de relapsía (es decir, reincidencia); esta ausencia de relapsos ilustra perfectamente la peculiaridad de esta región, hasta entonces al margen de la represión.

Únicamente tres hombres fueron arrestados, a pesar de representar casi la mitad de los denunciados en São Vicente. También podemos notar una cierta benevolencia en el caso de Manuel de Lucena, sindicado de haber practicado rituales judíos, como el kipur, entre otros, pero quien tan solo sería condenado a salir en el auto de fe con la cabeza descubierta y una vela en la mano, luego de lo cual habría de ser liberado. Se aduce en la sentencia que fue "por respeto a la calidad de la dicha persona" ("Proceso contra Manuel de Lucena", ANTT, TSO-IL/O28/07I73, f. IO9). En cambio, su mujer, sus cuñadas y su hermana pasarían varios años en prisión y otros más llevando el sambenito (véase figura I para una visión general).

\section{Conclusiones}

I. Lo primero que llama la atención cuando escuchamos los cientos de testimonios sobre las costumbres criptojudías en aquellas provincias fronterizas, es su visibilidad. Si se fuera estricto sobre el plano semántico, el criptojudaísmo allí podría deshacerse de su prefijo. El "error herético" tenía poco de secreto, estaba

I5 Aparecen en ese primer mandato los nombres de Branca do Porto, Beatriz Rodrigues, Clara de Lucena, Isabel de Lucena, Marquesa de Lucena, Maria Nunes, Clara Rodrigues, Joana Rodrigues y Simõa de Lucena. Todas son parientes.

16 Se trata de Ana Lopes, Branca do Porto y Antonia Brandõa (ANTT TSO-IL/O28/12145, TSO-IL/ 028/12153, TSO-IC/O25/O1745); la hermana de Ana, Constanza Lopes, había muerto en prisión y fue quemada en estatua (ANTT TSO-IL/O28/O4463). 
casi a los ojos de todos, a cielo abierto. En ese modesto pueblo que era São Vicente da Beira, 88 personas fueron denunciadas por actos de judaísmo. Esto en apenas siete días de visita (en realidad cinco días enteros y dos mediodías). En estas tierras no hay traza de ninguna otra herejía: ni protestantes ni alumbrados. Aquí el Santo Oficio tiene un solo problema, y es masivo: el criptojudaísmo.

2. No se puede dejar de resaltar la implicación y la eficacia del inquisidor Marcos Teixeira. Servidores como él siempre fueron determinantes en las fases ofensivas del Santo Oficio (pensamos, por ejemplo, en los primos Mañozca en Lima y México). En cuanto a los resultados, las estadísticas inquisitoriales hablan por sí solas: si en la década de 1570 solo hubo dos autos de fe públicos en Lisboa (I574 y I576), en la década siguiente, una vez terminada la visita, se cuentan quince. Por lo que hace a la comarca de Castelo Branco, la contribución del inquisidor Teixeira fue definitiva en las decenas de procesos que pudimos consultar; en cada uno de ellos aparecen textualmente los testimonios, reproducidos en las actas de acusación tal y como habían sido recogidos in situ. Presente en cada una de las audiencias, como atestigua su firma al final de cada documento, Teixeira aportó a sus colegas un volumen impresionante de acusaciones, listo para su utilización y exento de vicios jurídicos.

3. El cuadro sociológico, válido para toda la región, es el de una población profundamente dividida entre cristianos viejos y nuevos. Los denunciantes son cristianos viejos en cerca de 95\%; los que fueron denunciados son cristianos nuevos, en un porcentaje similar. Hasta la llegada del inquisidor, unos y otros parecen sin embargo haber cohabitado en relativa concordia; en todo caso no hay memoria de violencias físicas como las que habían sufrido los cristianos nuevos de Lisboa unas décadas atrás. Pero la separación parece bien marcada. Los matrimonios "mixtos", si no son extraordinarios, sí parecen raros. Difícil de pronunciarse definitivamente sobre un tema tan complejo y variable, pero entre los cristianos nuevos de esta región la recurrencia de la endogamia parece un signo inequívoco de resistencia a la asimilación.

El resultado de esas prácticas es que los cristianos nuevos aparecen como un cuerpo extranjero a los ojos de la población católica. Son así identificados de generación en generación y mirados con recelo; separados en la vida y hasta en la muerte, porque se entierran aparte. El resentimiento estuvo de alguna manera represado durante años en el seno de la población cristiana vieja, y con la llegada del Santo Oficio las esclusas se abrieron. Al celo religioso se sumaron los viejos rencores, las frustraciones y las envidias que dormían en el fondo de 
la memoria: algunas denuncias, como una contra la madre de Simóa de Lucena, relataban hechos ocurridos veinte ańos atrás (denuncia de Gil Antunez, Visitação, f. 566).

Dedicados al artesanado y al pequeño comercio, la inmensa mayoría de los cristianos nuevos vivía además en el casco urbano, a menudo en las calles de las antiguas juderías, lo que continuaba atándolos al pasado. Un panorama urbano que no los diferenciaba mucho de otros grupos cristianos nuevos de finales del quinientos, como por ejemplo los portugueses que colmaban la calle Sierpes en Sevilla. Pero la actitud no era la misma. En otras latitudes, el criptojudío portugués era un recién llegado que trataba siempre de mimetizarse para proteger su vida dual. Sabía que su seguridad y la de los suyos dependía del secreto. Una estrategia que parece poco afirmada entre los judaizantes de estas tierras, seguramente a causa de su importante peso demográfico y a la escasa represión inquisitorial. Esa confianza, algo temeraria, les permitió, sin embargo, tener también la fuerza para intervenir en el curso de los acontecimientos. Los cristianos nuevos de Fundão, en plena visita, se quejaron ante el inquisidor general porque Marcos Teixeira había empleado algunas palabras ofensivas. Allí mismo, un año más tarde, un grupo de vecinos osó atacar físicamente a dos meirinhos (oficiales de justicia) que tenían la intención de arrestar a unos judaizantes a la salida de la misa dominical (Garcia I7I-I97; Mea 242).

4. Si se observa la implicación de cada uno de los acusados, constatamos que una mujer, Simóa de Lucena, es el epicentro del grupo judaizante, o al menos del grupo más importante de practicantes de São Vicente (hubo dieciocho testigos que depusieron en su contra). También es el enlace con el grupo judaizante de Castelo Branco, en particular con sus seis concuñadas Lopes y las hijas de estas, todas condenadas. Y reencontramos en Simóa, como en su cuñada, Isabel Fernandes, el arquetipo de la mujer conocedora de la ley de Moisés y consagrada a su salvaguarda, tan presente en la historia del criptojudaísmo iberoamericano; esa matrona que los inquisidores que ejercieron en México llamaban una "dogmatista”. En ese mundo secreto, la mujer se convirtió en el relevo imprescindible. Como casi todas ellas, aparte de sus conocimientos y su activismo religioso, Simốa mostró también una gran resistencia física, confesando únicamente en el potro de tortura ${ }^{17}$. Pasó tres años en prisión y otros tres llevando el sambenito, el cual le fue levantado por el clérigo de São

I7 Isabel de Lucena, nieta de Simõa, fue arrestada en Sevilla en I604, pero "venció" la tortura, es decir, que no confesó; abjuró de vehementi y pagó una multa de 200 ducados (A HN, Inq., leg. 2075, f. 7). 
Vicente después de la misa dominical del 6 de diciembre de 1587, delante de toda la población ("Proceso contra Simóa de Lucena", ANTT, TSO-IL/O28/132238).

Fue Simóa quien garantizó la transmisión de la fe secreta en la que ella había sido iniciada a su vez por su tío, Simão de Lucena, con la anuencia de sus padres. Tenía entonces Is años; 48 cuando fue arrestada.

5. Algunos descendientes directos de Simóa de Lucena llegaron al Nuevo Reino de Granada unos lustros más tarde, donde habrían de practicar en secreto la religión de sus ancestros. Como su sobrino Pedro Lopes, cuya vida ilustra perfectamente nuestra historia, porque siendo un niño de ocho años en la época de la visita, presenció la detención de toda su familia; se embarcó años más tarde hacia el Nuevo Mundo y terminó instalándose en el pueblo de Zaragoza, Antioquia, donde casi medio siglo después sería arrestado por el comisario del Tribunal de Cartagena de Indias. A este puerto del Caribe llegaron los nietos de Simóa: Luis y Manuel Franco, Isabel de Lucena, Ruy Dias Lemos y Luis Dias Lucena. Siete judaizantes originarios de São Vicente serían procesados en México en 1596, entre ellos Manuel de Lucena, condenado a morir en la hoguera. En I600, el Tribunal de Lima quemaba a su vez a Baltasar de Lucena y enviaba a las galeras a su hermano Gaspar (AHN, Inq., libro IO29, ff. 6I-65).

La relación de causalidad entre la visita y la emigración es pues indiscutible, y ella se acentúa en las primeras décadas del siglo xvir; uno de los que huyó y llegó a México dijo que Castelo Branco se había quedado "despoblado" (AGNM, Inq., vol. 426, f. 544 v.). Por una ironía de la historia, varios de esos fugitivos que huyeron de Castelo Branco lograron una ascensión social que jamás hubieran podido imaginar en aquellos condados olvidados de Portugal, construyendo en el exilio español emporios comerciales y financieros ${ }^{18}$, otros más convirtiéndose en negociantes importantes de la Carrera de Indias ${ }^{19}$.

Toda la historia del criptojudaísmo parece concentrarse en ese minúsculo pueblo de São Vicente, enigmático vivero del criptojudaísmo americano: vio nacer mártires y hasta un convertido católico convencido. Porque también allí nació y creció el más nefasto de los malsines americanos: Gaspar de Robles, un joven judaizante que de su propia voluntad decidió colaborar con el Santo Oficio

I8 Entre los más sobresalientes se encuentran Marcos Fernández Monsanto, tesorero del Almojarifazgo Mayor y de Indias en Sevilla, Diego Núñez Belmonte o Francisco Rodríguez Penamacor.

19 Como García de Lucena, Francisco López Sevilla, Simón Váez Sevilla, Gregorio Díaz de Lucena, Damián de Lucena, Manuel Enríquez y Francisco López Méndez. En total 258 portugueses fueron naturalizados en la primera mitad del seiscientos (Aguado I8). 
mexicano, convirtiéndose así en el artífice de la destrucción de la comunidad judaizante entre 1642 y $1649^{20}$.

A mediados del siglo xviı, la experiencia del criptojudaísmo en la América espańola tocaba a su fin. Al menos según la documentación inquisitorial. La matriz original, en cambio, la portuguesa, permaneció inamovible. La restauración genealógica de la familia Lucena, a través de decenas de procesos inquisitoriales, nos permitió encontrar, casi dos siglos después de la visita, a los descendientes de aquellos primeros condenados. Fieles todavía a la fe de sus ancestros y apegados a pesar de todo a esas tierras que bordean la frontera con España. La América española había desaparecido de su horizonte, la migración se orientaba entonces, naturalmente, hacia el Brasil.

El Santo Oficio parece más eficaz que nunca, mediando el siglo XviıI, los judaizantes condenados se cuentan otra vez por decenas. Entre ellos se encuentra el padre del ilustre médico António Nunes Ribeiro Sanches, muerto en el exilio francés en 1783 , después de haber servido a la emperatriz de Rusia ${ }^{21}$ (ANTT, TSO-IL/O28/07906). En ese reconocido hombre de ciencia se oye el eco de nuestra familia original, porque su abuelo fue Pedro Henriques Lucena, originario de São Vicente da Beira, mientras que su abuela fue la bisnieta de una Perpetua de Lucena. Esta fue la hermana de Pedro Lopes, aquel ancestro que, en I625, preso también de melancolía, había muerto en la celda número ocho de la Inquisición de Cartagena de Indias ("Proceso contra Pedro Lopes", AHN, Inq., leg. I620, n. ${ }^{\circ}$ 6, f. 24 r.).

20 Su proceso desapareció, pero sabemos que fue reconciliado, seguramente en auto particular. Sus declaraciones aparecen en varios procesos, por ejemplo, en el de Gaspar Méndez (AGN M, Inq., vol. 410 , ff. 550 v. -552 v.).

2I Escribió un texto de una gran lucidez sobre la separación entre cristianos nuevos y viejos que todavía fracturaba a la sociedad portuguesa (Ribeiro). 


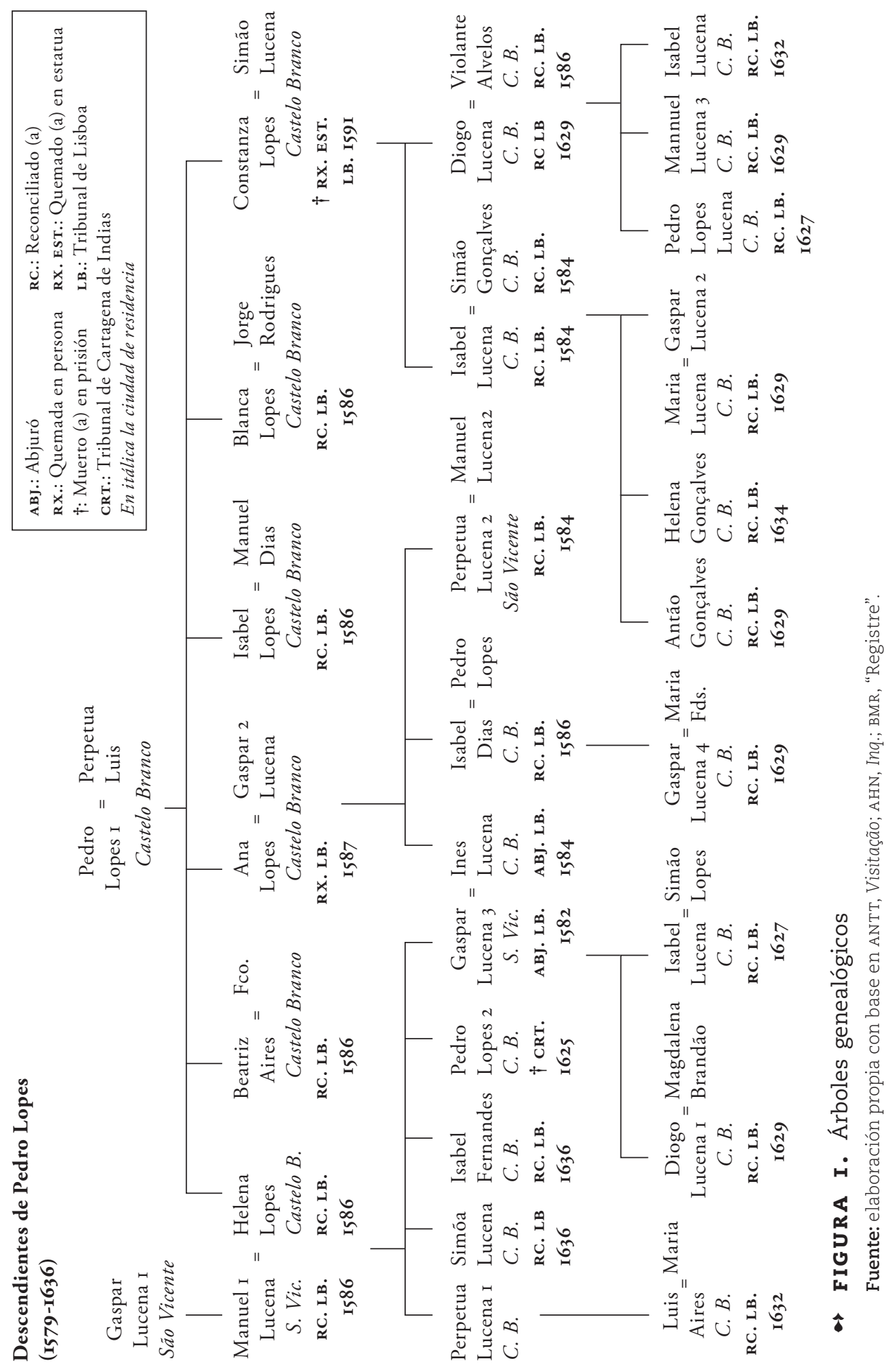




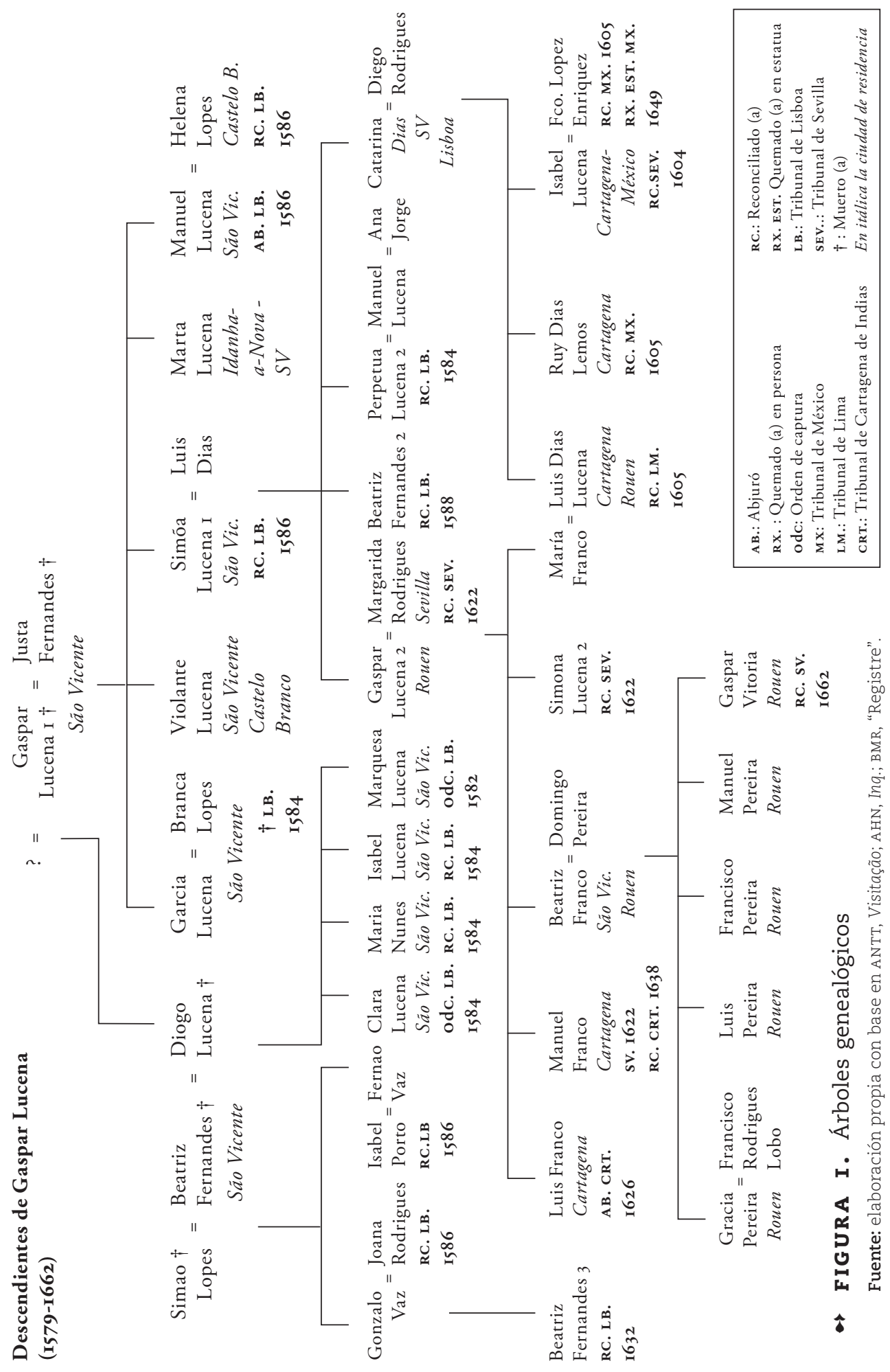




\section{. \\ B I B L I O G R A F í A}

\section{F U E N T ES PRIMARIAS}

\section{A. Archivos}

Arquivo Nacional da Torre do Tombo, Lisboa, Portugal (ANTT).

Tribunal do Santo Oficio.

Livro $I^{\circ}$ das denúncias da visitação do Santo Oficio nas ilhas dos Açores, Alentejo e

Beira, TSO-IL/038/0794, 39I folios (Visitação).

"Proceso contra Simõa de Lucena", TSO-IL/O28/13238.

"Proceso contra Isabel de Lucena", TSO-IL/O28/03139.

"Proceso contra Gaspar de Lucena", TSO-IL/028/01646.

"Proceso contra Manuel de Lucena", TsO-IL/028/07173.

"Proceso contra Perpetua de Lucena", TSO-IL/O28/1324I.

"Proceso contra Inés de Lucena”, TSO-IL/O28/0423I.

"Proceso contra Joana Rodrigues", TSO-IL/O28/09907.

"Proceso contra Ana Lopes", TSO-IL/O28/12145.

"Proceso contra Constanza Lopes", TSO-IL/O28/04463.

"Proceso contra Antonia Brandõa", TSO-IC/025/01745.

"Proceso contra Beatriz Henriques", TsO-IC/025/04035.

"Proceso contra Diogo de Lucena", TSO-IL/O28/01397.

"Proceso contra Antão Gonçalves", Tso-IL/028/02669.

"Proceso contra Maria Nunes", TSO-IL/028/17990.

"Proceso contra Branca Lopes", TSO-IL/O28/1217I.

"Proceso contra Clara de Lucena", TSO-IL/O28/07439.

"Proceso contra Isabel de Lucena", TSO-IL/028/03117.

"Proceso contra Simão Gonçalves", TSO-IL/O28/14045.

"Proceso contra Beatriz Fernandes", TSO-IL/028/00890.

"Proceso contra Helena Lopes", TSO-IL/O28/12164.

"Proceso contra Beatriz (Brites) Aires", TSO-IL/028/05100.

"Proceso contra Isabel Lopes", TSO-IL/O28/I217I.

"Proceso contra Isabel Fernandes", TSO-IL/028/03244.

"Proceso contra Isabel Días", TSO-IL/028/06055.

"Proceso contra Pedro Lopes de Lucena", TsO-IL/028/08387.

"Proceso contra Isabel de Lucena (I627)", TSO-IL/O28/02530.

"Proceso contra Antão Gonçalves", Tso-IL/028/02669.

"Proceso contra Helena Gonçalves", TSO-IL/028/1066I. 


\footnotetext{
“Proceso contra Gaspar de Lucena (1629)”, TSO-IL/028/03743.

"Proceso contra Maria de Lucena (I629)", TSO-IL/028/05503.

"Proceso contra Luis Aires", TSO-IL/028/10797.

“Proceso contra Violante de Alvelos”, TSO-IL/028/06021.

“Proceso contra Manuel de Lucena (I629)", TSO-IL/O28/OI8OI.

"Proceso contra Isabel de Lucena (I632)", TSO-IL/028/06737.

“Proceso contra Simõa de Lucena (I636)", TSO-IL/o28/02442.
}

\section{Archivo Histórico Nacional de España $(A H N)$.}

Inquisición (Inq.).

"Proceso contra Isabel de Lucena", Tribunal de Sevilla, leg. 2075 , f. 7.

"Proceso contra Luis Dias Lucena", Tribunal de Lima, libro I029, ff. 294 v.-296 r.

"Proceso contra Manuel Franco Días", Tribunal de Cartagena de Indias, libro IIO3 (cuadernillo de Io folios sin numerar); leg. I60I, n. ${ }^{\circ} 8$, f. $38 \mathrm{v}$.

"Proceso contra Pedro Lopes", Tribunal de Cartagena de Indias, leg. I620, n. 6.

"Procesos contra Luis Franco", Tribunal de Cartagena de Indias, leg. I620, n. 5 y n. 7.

\section{Archivo General de la Nación de México (AGNM).}

Inquisición (Inq.).

"Relaciones de causa", vol. 426, f. 544 v.

"Proceso contra Simón Váez", Sevilla, vol. 398.

"Proceso contra Gaspar Méndez", vol. 410.

Bibliothèques Municipales de Rouen (Rouen, Francia).

"Registre de la Chambre des Comptes de Normandie pour noblesse, légitimation et naturalité, depuis 1578 jusques en I653", cote Ms g 48, ff. I5 y I6.

\section{B. IMPRESOS}

Aguado, Pedro de. Recopilación historial. 1581. Bogotá: Imprenta Nacional, 1906.

\section{I F U E N T ESSECUNDARIA S}

Aguado de Los Reyes, Jesús. "El apogeo de los judíos portugueses en la Sevilla Americanista”. Cuadernos de Estudios Sefarditas, n. ${ }^{\circ}$, 2005, pp. I35-157.

Alves Dias, João José. A Beira interior em 1496 (Sociedade, Administração e Demografia). Ponta Delgada: Universidade dos Açores, 1982. 
Amiel, Charles. "Les cent voix de Quintanar". Revue de l'histoire des religions, t. 21 8, n. 4 , 200 I, pp. 487-577.

“Caderno da gente e Rendas da Beira”. Os Forais e Populaçao nos seculos XV e XVI, transcrito por Luis Fernando Carvalho Dias. http://covilhasubsidiosparasuahistoria.blogspot. com/20II/II/covilha-os-forais-e-populacao-nos_24.html. Consultado el 9 de septiembre del 2018.

Cantera Montenegro, Enrique. "Reminiscencias judías en las creencias supersticiosas y prácticas mágicas de los judeoconversos castellanos en el tránsito de la Edad Media a la Moderna". Las minorias: ciencia, magia y superstición en España y América (siglos $X V$ al XVII), editado por Rica Amrán. Santa Barbara: Publications of eHumanista, 2015, pp. II2-I22.

Castelo Branco, Manuel da Silva. "A comuna judaica da vila de Castelo Branco (I38I-I 496)". Actas das Primeiras Jornadas do Património Judaico da Beira interior. Trancoso e Belmonte: 2008 , pp. 7-29.

Escobar Quevedo, Ricardo. Inquisición y judaizantes en América española, siglos XVI-XVII. Bogotá: Universidad del Rosario, 2008.

Ferro Tavares, Maria José. “Os judeus da Beira Interior". Sefarad, vol. 63, n. ${ }^{2}$, 2003 , pp. 369-4II.

Goldberg, Sylvie Anne. "Les lectures mortuaires des Juifs dans les communautés ashkénazes (XVII ${ }^{\mathrm{e}}$-XVIII ${ }^{\mathrm{e}}$ siècles)". Revue de l'histoire des religions, t. 204, n. ${ }^{\circ}$, I987, pp. 249-278.

García, María Antonieta. “Um motim no Fundão em I580”. Actas das Primeiras Jornadas do Património Judaico da Beira interior. Trancoso e Belmonte: 2008, pp. I7I-197.

Marcocci, Giuseppe y José Pedro Paiva. Historia da Inquisiçào portuguesa (I536-I82I). Lisboa: Esfera dos Livros, 2013.

Mas Belén, Bienvenido. "El ritual funerario como expresión de condición religiosa y socioeconómica entre los siglos XVI-XVII: los cristianos viejos y los moriscos crevillentinos (I)". Panta Rei: Revista de Ciencia y Didáctica de la Historia, n. 2, 1996, pp. 49-59.

Mea, Elvira Cunha de Azevedo. A Inquisiçào de Coimbra no século XVI. A instituição, os homens e a sociedade. Lisboa: Fundação Eng. António de Almeida, 1997.

Medina, José Toribio. La Inquisición en Cartagena de Indias. Bogotá: Carlos Valencia Editores, 1978 .

Oltean, Crina Adriana. "A Denúncia ao serviço da fé ou da vingança? a delação inquisitorial e os seus efeitos”, tesis de maestría en Historia, Universidade de Lisboa, 2014.

Pastore, Stefania. "Mujeres, lecturas y alumbradismo radical: Petronila de Lucena y Juan del Castilla”. Historia Social, n. ${ }^{5}$, 2007 , pp. 5 I-73. $^{-}$ 
Pereira, Isaías da Rosa. "Notas sobre a Inquisição em Portugal no século Xvi”. Lusitania Sacra, t. 10, 1978, pp. 269-275.

Ribeiro Sanches, António Nunes. Cristãos novos e Cristãos velhos em Portugal. Covilhà: Universidade da Beira Interior, 2003.

Schwartz, Stuart. All Can Be Saved, Religious Tolerance and Salvation in the Iberian Atlantic World. Yale University Press, 2008. 